\title{
A cDNA ENCODING A MUSCLE-TYPE TROPOMYOSIN CLONED FROM A HUMAN EPITHELIAL CELL LINE: IDENTITY WITH HUMAN FIBROBLAST TROPOMYOSIN TM1
}

\author{
G. L. Prasad, Scott Meissner, Donald G. Sheer, and Herbert L. Cooper*
}

Cell and Molecular Physiology Section, Laboratory of Tumor Immunology and Biology, National Cancer Institute, Bethesda, Maryland 20892

Received April 30, 1991

SUMMARY: Tropomyosins (TM) expressed by human epithelial cells have only recently been characterized, and no sequence data for them has appeared. We cloned a cDNA encoding a high molecular weight, muscle-type TM from a LS174T human colon carcinoma epithelial cell cDNA library. On sequence analysis this cDNA (TMe1) was virtually identical to the previously reported sequence for human fibroblast TM1 encoded by the hTMB gene. Expression of TM1/TMe1 mRNA and protein are low in epithelial cells compared with fibroblasts. The results indicate that cells of different developmental lineages (entodermal and mesodermal) can produce identical TMB gene splice products while regulating expression of those transcripts in a lineage-specific way. 1991 Academic Press, Inc.

Tropomyosins (TM) are a family of microfilament-associated cytoskeletal proteins expressed in all cells studied to date. In skeletal muscle TMs are known to play an important part in contractility of the muscle fiber (1). In smooth muscle and non-muscle cells their function is more obscure but roles in contractility, motility, maintenance of cellular conformation and neoplastic transformation have been postulated (1-9).

Four genes have been identified thus far which code for human TMs and have been designated hTM $\alpha, \mathrm{hTM}, \mathrm{hTM}$ nm, and $\mathrm{hTM}_{\mathrm{pl}}(10)$. The expression of the various genes is developmentally regulated so that cells of different embryonic lineages express different members of the gene set. Thus, skeletal muscle cells express products of the hTM $\alpha$, hTM $\beta$ and $\mathrm{hTM}_{\mathrm{nm}}$ genes. Non-muscle mesodermal derivatives such as fibroblasts express products of the same set of genes which, however, differ from the forms expressed in muscle cells because of alternative splicing. Fibroblasts additionally express a non-muscle TM derived from the $h \mathrm{hM}_{\mathrm{pl}}$ gene (10). It has been generally observed that where cells of different developmental lineages express transcripts of the same TM gene, these transcripts differ in a lincagc-specific way due to alternative splicing, alternative transcription initiation sites, or both (11-13). Rat smooth muscle and fibroblasts express the identical processed transcript of the TMB gene (14), but these cells are both of mesodermal origin.

\footnotetext{
* To whom correspondence and reprint requests should be addressed.
} 
TMs expressed by human epithelial cells have not been well studied and, to date, no cDNA clones or sequence data have been reported. It is not known, therefore, which genes are active in epithelial cells or whether they are characterized by a distinct set of alternative splice products. In this paper we report the cloning and sequencing of a full length cDNA for a muscle-type TM from human epithelial cells.

\section{MATERIALS AND METHODS}

Cell culture: Human diploid skin fibroblast cell strains WS1 and MRC5 were obtained from the American Type Culture Collection, Rockville, MD. Colon adenocarcinoma cell line LS174T was supplied by Dr. J. Greiner, Laboratory of Tumor Immunology and Biology, National Cancer Institute. All cells were maintained in culture in Dulbecco's modified Eagle's Minimal Essential Medium supplemented with $10 \%$ fetal bovine serum, penicillin and streptomycin $(50 \mathrm{u} / \mathrm{ml}$ and $50 \mu \mathrm{g} / \mathrm{ml}$, respectively). LS174T displays numerous biochemical characteristics of epithelial cells, such as carcinoembryonic antigen production (15), tumorspecific mucin production $(16,17)$, and expression of epithelial cytokeratins (18).

Metabolic Labeling and Preparation of Proteins: Monolayers were washed with PBS and labeled for $4 \mathrm{hrs}$ with methionine-free culture medium supplemented with [ $\left.{ }^{35} \mathrm{~S}\right] \mathrm{met}(100$ $\mu \mathrm{Ci} / \mathrm{ml} ;>1160 \mathrm{Ci} / \mathrm{mmol}$; New England Nuclear) and $5 \%$ dialyzed fetal bovine serum. Whole-cell, heat-stable, and immunoprecipitated proteins were prepared from labeled cells as described (19).

Anti-TM antiserum: Smooth muscle TM was purified from fresh chicken gizzard as described (20). Purity of the product was estimated by one- and two-dimensional electrophoresis. Polyclonal rabbit antiserum was raised to the purified protein by standard immunological methods. The rabbit serum was used directly and was not further purified. The antiserum was found to react very strongly and specifically with higher $M_{r}$ muscle-type TMs from human and murine fibroblasts and epithelial cells. It reacts poorly with the lower $\mathbf{M}_{\mathbf{r}}$ nonmuscle forms of TM.

Library construction and subcloning: Total RNA was prepared from LS174T cells by the guanidine-phenol-chloroform method and polyadenylated RNA was isolated by oligo(dT) cellulose chromatography (21). Beginning with $5 \mu \mathrm{g}$ of mRNA, a library of $10^{8}$ lambda-ORF8 phage clones with directionally inserted BamH1 - HindIII CDNA fragments was prepared as described $(21,22)$. Approximately $10^{6}$ plaques were screened for TM expression on nitrocellulose plaque lifts by standard techniques using anti-TM antiserum (1:1000) and ${ }^{125} \mathrm{I}-$ labeled goat anti-rabbit second antibody.

After 2 rounds of plaque purification, a strongly reactive phage clone was obtained. The CDNA insert within the lambda-ORF8 phage clone was subcloned into the plasmid expression vector pSMK16 using an in vivo subcloning technique (Meissner and Berman, unpublished). Briefly, $E$. coli MC1061 containing pSMK16 were grown overnight at $37^{\circ}$ on an LB plate containing kanamycin $(10 \mu \mathrm{g} / \mathrm{ml})$. A single colony was inoculated into $5 \mathrm{ml}$ of $\mathrm{LB}$ broth and approximately $10^{6} \mathrm{pfu}$ of the recombinant lambda-ORF8 phage was added. Homologous recombination between the phage and plasmid pSMK 16 was allowed to proceed for 8 hours and then the culture was diluted $1: 10$ into LB containing $100 \mu \mathrm{g} / \mathrm{ml}$ powdered ampicillin. After 12 hours of growth, the culture was again diluted $1: 10$ into LB containing $1 \mathrm{mg} / \mathrm{ml}$ powdered ampicillin. After 12 hours of growth the recombinant plasmid containing both the ampicillin resistance gene and the cDNA insert from the phage was rescued using a plasmid mini-prep procedure (21). Ampicillin resistant, kanamycin sensitive colonies were isolated and the insert characterized.

DNA Sequencing: For bidirectional sequencing, the cDNA insert was subcloned from pSMK 16 into PUC18 by standard techniques (21). Sequencing was carried out in both directions by the dideoxy chain termination technique (23).

Two dimensional polyacrylamide gel electrophoresis: Samples were prepared and analyzed by 2-dimensional polyacrylamide gel electrophoresis as described (9). First dimension ampholytes (LKB) were $1 \% \mathrm{pH} 3.5-10$ and $1 \% \mathrm{pH} 4-6$. First dimension gels were run for 11000 voltage hours. Second dimension gels were $12 \%$ polyacrylamide. 
Quantitation of radiolabeling in 2-dimensional gels and northern blots: Radioactivity from [35S]methionine in dried 2-dimensional protein gels or from ${ }^{32} \mathrm{P}$ in northern blots was scanned directly with an AMBIS 2-dimensional beta scanning system (Automated Microbiological Systems, Inc., San Diego, CA). Radioautographs were also prepared for reference and documentation.

Northern blot analysis: RNA preparation, electrophoresis in agarose-formaldehyde denaturing gels, and northern blot analysis were performed as described (21). Probes were radiolabeled with ${ }^{32} \mathrm{P}$ by the random primer technique (24). TM cDNA probe $\mathrm{p} 1558$, specific for the 1.1 kB TM1 mRNA expressed by human fibroblasts (11), was kindly provided by Dr. A. R. MacLeod, Cambridge. Quantitation of radioactivity hybridized to specific bands was performed with the AMBIS beta-scanning system.

\section{RESULTS AND DISCUSSION}

The sequence analysis of the anti-TM reactive clone (TMe1) derived from LS174T colon epithelial cells is presented in figure 1, where it is compared with the sequence for human fibroblast TM1 published by MacLeod et al (11). TMe1 has a 89-nucleotide 5 ' untranslated region, which is 29 nucleotides shorter than that of TM1. This includes one missing guanine nucleotide located two nucleotides $5^{\prime}$ to the initiation codon. This residue is also absent from the corresponding rat gene which is otherwise identical in this region (14). The relatively short (70-nucleotide) 3 ' untranslated region of TMe1 lacks 4 nucleotides immediately preceding the poly-A tail of TM1. The corresponding rat sequence lacks these same 4 nucleotides plus an additional one in this region (14). The entire coding region of 852 nucleotides and the remainder of the $5^{\prime}$ and $3^{\prime}$ untranslated regions are identical, base for base, to TMI cDNA. The virtual identity of these cDNAs indicates that they are products of the same gene (hTMB) arising through the same alternative splicing pathway. The minor differences noted are probably due to allelic variation. The observation that these same differences are present in the homologous rat sequence suggests that the variant we have cloned is a common and highly conserved one.

To determine the relative level of expression of the $1.1 \mathrm{kB}$ mRNA for TM1/TMe1 in LS174T cells, a northern blot of mRNAs from LS174T epithelial cells and from MRC5 and WS1 fibroblasts was hybridized successively with TMe1 DNA and with probe p1558, which is specific for the TM1 mRNA of human fibroblasts (11). TMel and p1558 produced identical hybridization patterns (fig. 2A,B). A small amount of $1.1 \mathrm{kB}$ mRNA was detected in LS174T compared with large amounts in the fibroblast cell lines. Prolonged film exposure was required to detect this band in LS174T RNA. The blot was also probed with a B-actin probe (fig. 2C) and the results were quantitated (see Methods). In figure 2D, the level of $1.1 \mathrm{kB}$ mRNA is shown, normalized for actin level on the blot. It is evident that the $1.1 \mathrm{kB}$ TM1/TMe1 mRNA is expressed at considerably lower levels in LS174T epithelial cells than in either of the fibroblast lines.

TMel and p1558 also hybridized to a $1.7 \mathrm{kB}$ band (fig. 2A,B). This band was barely detectable in LS174T but was clearly seen in the fibroblast mRNAs. MacLeod et al have reported a $2.0 \mathrm{kB}$ RNA which behaves similarly to the $1.7 \mathrm{kB}$ form we have observed and may, in fact, be identical to it (26). They have identified the $2.0 \mathrm{kB}$ mRNA as a smoothmuscle-type TM encoded by the hTM $\alpha$ gene (11). 
TMe 1 CGCCTGCCACCGGTGCACCCAGTCCGCTCACC

TM1 TGCTGCTCTCCTCCCGCTCCGTCCTCCT CAGCCCAGTCCGTCCGGTCCTCACCGCCTGCCGGCCGGCCCACCCCCCACCGCAG $\cdot \mathrm{CCAT}$ - - - - - - - - - - - GGACGCCATCAAGAAGAAGATGCAGATGCTGAAGCTGGACAAGGAGAACGCCATCGACCG

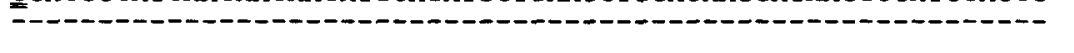
CGCCGAGCAGGCCGAAGCCGACAAGAAGCAAGCTGAGGACCGCTGCAAGCAGCTGGAGGA

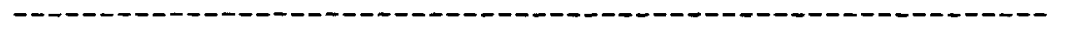
GGAGCAGCAGGCCCTCCAGAAGAAGCTGAAGGGGACAGAGGATGAGGTGGAAAAGTATTC - - - - - - - - - - TGAATCCGTGAAGGAGGCCCAGGAGAAACTGGAGCAGGCCGAGAAGAAGGCCACTGATGC Т TGAGGCAGATGTGGCCTCCCTGAACCGCCGCATTCAGCTGGTTGAGGAGGAGCTGGACCG

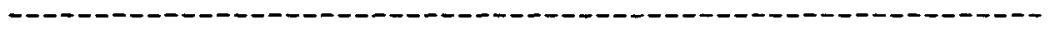
GGCCCAGGAGCGCCTGGCTACAGCCCTGCAGAAGCTGGAGGAGGCCGAGAAGGCGGCTGA

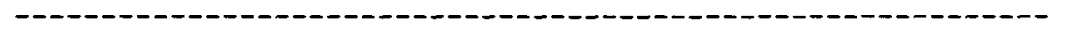
TGAGAGCGAGAGAGGAATGAAGGTCATCGAAAACCGGGCCATGAAGGATGAGGAGAAGAT - - - - - - GGAACTGCAGGAGATGCAGCTGAAGGAGGCCAAGCACATCGCTGAGGATTCAGACCGCAA

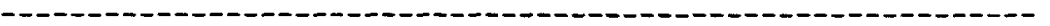
ATATGAAGAGGTGGCCAGGAAGCTGGTGATCCTGGAAGGAGAGCTGGAGCGCTCGGAGGA САGGG GAGGGCTGAGGTGGCCGAGAGCCGAGCCAGACAGCTGGAGGAGGAACTTCGAACCATGGA CCAGGCCCTCAAGTCCCTGATGGCCTCAGAGGAGGAGTATTCCACCAAAGAAGATAAATA CСAGGCCCTCAAGTCCCTGATGGCCTCAGAGGAGGAGTATTCCACCAAAGAAGATAAATA TGAAGAGGAGATCAAACTGTTGGAGgAGAAGCTGAAGGAGGCTGAGACCCGAGCAGAGTT

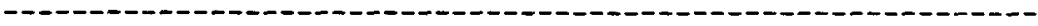
TGCCGAGAGGTCTGTGGCAAAGTTGGAGAAAACCATCGATGACCTAGAAGAGACCTTGGC

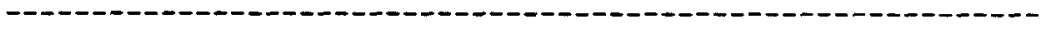
CAGTGCCAAGGAGGAGAACGTCGAGATTCACCAGACCTTGGACCAGACCCTGCTGGAACT САG

CAACAACCTGTGAGGGCCAGCCCCACCCCCAGCCAGGCTATGGTTGCCACCCCAACCCAA 991 СААСААССТ TAAAACTGATGTTACTAGCC $\cdots$ (AAA...) 1011 TAAAАСТ

Figure 1. Nucleotide sequence of human epithelial cell TMe1 compared with fibroblast TM1 (11). Nucleotide identity is indicated by a hyphen in the TM1 row. Initiation and termination codons are doubly underlined; poly-A addition signal is singly underlined.

The coding region of TMe1 is identical to that of TM1, and therefore should code for a protein in LS174T cells identical to TM1. Two dimensional IEF/SDS-PAGE electrophoresis of immunoprecipitated and heat-stable proteins metabolically labeled with [ ${ }^{35}$ ] $]$ met was used to compare the tropomyosins expressed by LS174T epithelial cells with those expressed by WS1 fibroblasts (fig. 3). Immunoprecipitation reproducibly revealed 6 tropomyosin isoforms in LS174T cells (fig. 3A). These were designated TM39, 38, 35, 33a, 33b, and 32, corresponding to their apparent $\mathbf{M}_{\mathbf{r}}$. This pattern is essentially identical to that reported by us 


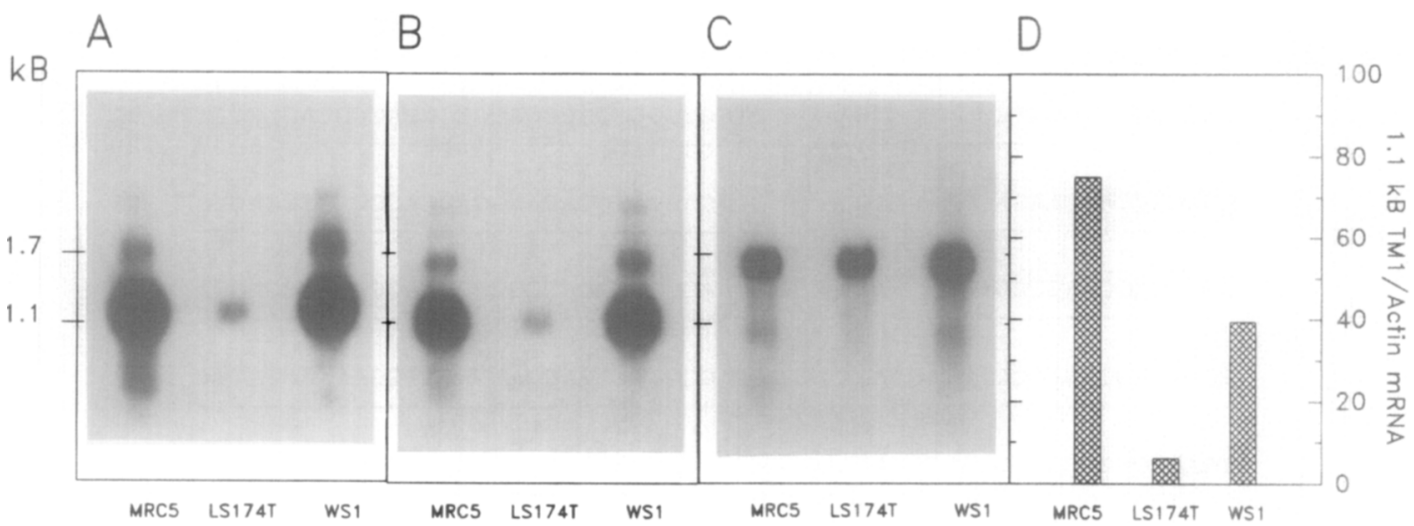

Figure 2. Northern blot analysis of TMel mRNA expression in LS174T epithelial cells versus MRC5 and WS1 fibroblasts. In each lane, $4 \mu \mathrm{g}$ of poly-A ${ }^{+}$RNA was separated by agarose gel electrophoresis and blotted to a nylon membrane. Blots were probed sequentially with TMel cDNA, probe p1558 which is specific for the fibroblast TM1 isoform (11), and actin cDNA. Radioactivity hybridizing to $1.1 \mathrm{kB}$ and actin bands was quantitated. $A$. TMel probe. $B$. p1558 probe. $C$. Actin probe. $D$. Quantitation of TMel mRNA expression $(1.1 \mathrm{kB}$ band radioactivity/actin band radioactivity).

for TMs expressed by diploid human mammary epithelial cells (19) and is apparently a common one for human epithelial cells. TM39 and TM35 have electrophoretic mobilities identical to those of fibroblast TM1 and TM3, respectively (fig. 3B). TM38 and TM32 have no counterparts in fibroblasts and may be encoded by epithelial cell-specific alternative splice products or transcripts of previously undescribed genes. No counterpart of fibroblast TM2 was detected in LS174T cells, although a small amount of it was noted previously in human mammary epithelial cells (19). Evidently, the protein encoded by TMe1 in LS174T cells is TM39. Elsewhere we have presented additional evidence that TM39 and TM1 are the same protein: human mammary carcinoma cell lines generally fail to express this isoform and also lack expression of the $1.1 \mathrm{kB}$ TM1/TMel mRNA (19).

The anti-tropomyosin serum we used preferentially binds to higher $M_{r}$ muscle-type TMs, so that the relative expression of the various isoforms is not accurately represented in the immunopreciptated preparation. The relative synthesis of the various isoforms is shown in heat-stable preparations (fig. $3 C, D$ ), where it is evident that the most prominently expressed TM isoform in LS174T cells is the lower $M_{r}$ (nonmuscle-type) TM33a. In WS1 fibroblasts, the non-muscle TMs (TM4 and TM5) were not expressed as prominently as the muscle-types (TM1, TM2 and TM3). Thus, in addition to expressing certain TM isoforms not found in fibroblasts, epithelial cells also differ from fibroblasts in the comparative levels of expression of the non-muscle and muscle-type isoforms.

The level of synthesis, relative to total protein synthesis, of TM39 or TM1 in LS174T epithelial cells and in MRC5 and WS1 fibroblasts was determined by quantitation of 2dimensional gels of whole-cell proteins (fig. 4; gels not shown). When expressed as a fraction of total protein resolved on the gel, LS174T epithelial cells were found to synthesize small amounts of TM39 compared to TM1 synthesis in fibroblasts. This is consistent with the low 


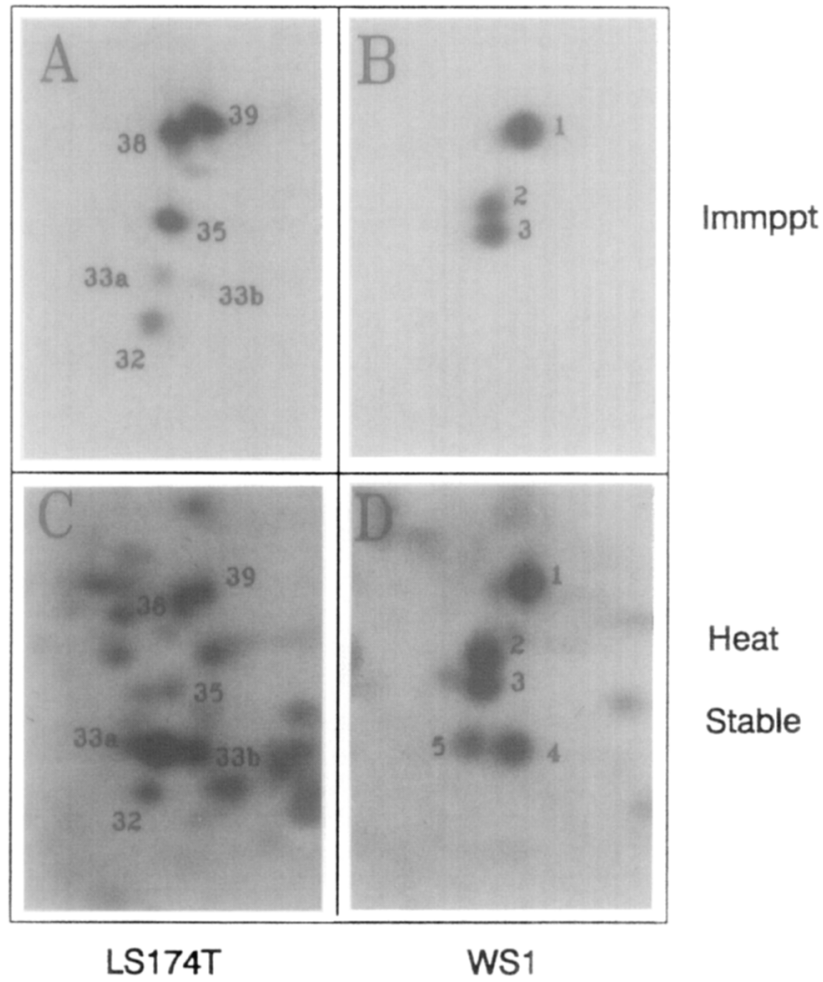

Figure 3. Tropomyosins expressed by LS174T epithelial cells compared with those expressed by WS1 fibroblasts. Cells were metabolically labeled with $\left.{ }^{35} S\right]$ methionine and cell lysates were prepared for immunoprecipitation of tropomyosins or for analysis of heat-stable proteins. Proteins were analyzed by 2-dimensional IEF-polyacrylamide gel electrophoresis and subjected to radioautography. Regions of gels containing tropomyosins are shown $\mathbf{M}_{\mathrm{r}}$ 25000-45000; pI 4-5). $A, B$ : Immunoprecipitates. $C, D$ : Heat stable proteins. $A, C$ : LS174T cells. $B, D$ : WS1 fibroblasts. Tropomyosins expressed by LS174T cells are numbered according to apparent $\mathbf{M}_{\boldsymbol{r}}$; fibroblast tropomyosins are numbered according to standard nomenclature.

level of TMe1 mRNA expression noted above (fig. 2D). Since expression of TM38 is in the same range as that of TM39 and TM35 is expressed at a lower level than TM39 (fig. 3A), it is apparent that muscle-type tropomyosins in general are poorly expressed in epithelial cells when compared with fibroblasts.

\section{CONCLUSIONS}

Our results indicate that LS174T epithelial cells express a mRNA that is a transcript of the hTMB gene which has undergone identical splice-processing to that for the mRNA encoding TM1 fibroblast tropomyosin. It not only encodes the identical amino acid sequence to TM1 but, except for a single missing nucleotide in the $5^{\prime}$ untranslated region and 4 fewer nucleotides at the extreme $3^{\prime}$ end, is identical to the TM1 cDNA originally cloned by MacLeod et al. from fibroblasts (11). The expression in epithelial cells of a $1.1 \mathrm{kB}$ mRNA, hybridizing to the TM1-specific probe, p1558, has been reported previously (11). Our observations demonstrate that this transcript is indeed identical to that expressed by fibroblasts, 


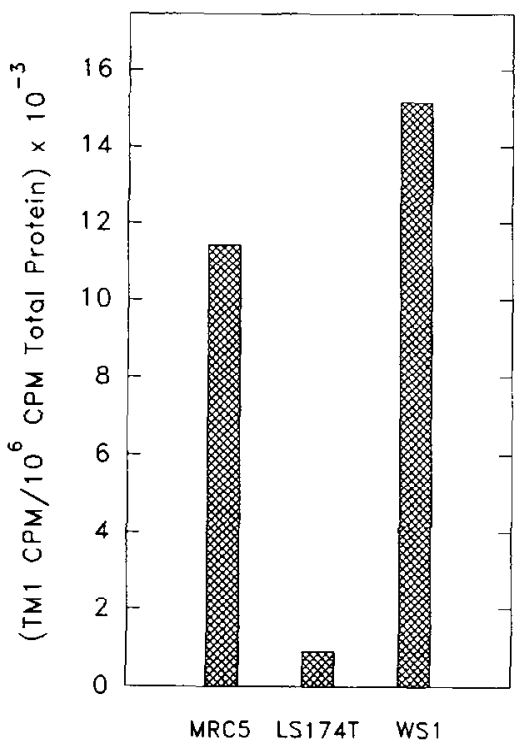

Figure 4. Quantitation of TM1 protein expression. LS174T epithelial cells, WS1 and MRC5 fibroblasts were metabolically labeled with [35]methionine and whole-cell proteins were analyzed by 2-dimensional IEF-polyacrylamide gel electrophoresis. Gels were scanned with the AMBIS radioanalytic imaging system and quantitation of TM1 (TM39) expression was performed together with measurement of radioactivity in all resolved proteins. Results are expressed as CPM in TM1/106 CPM in total protein.

thus providing conclusive evidence that the same splice-processing strategy is used by cells of different embryonic lineages (mesodermal and entodermal) in the production of hTMB gene transcripts.

The level of expression of TM1/TMe1 mRNA is much lower in LS174T epithelial cells than in fibroblasts, which agrees with previous findings of MacLeod et al (11). This correlates with similarly low expression of the related TM protein, and indeed, of all muscle-type TMs, in epithelial cells. Thus, there is cell lineage-dependent regulation of the level of expression of the hTMß gene.

\section{ACKNOWLEDGMENT}

The expert technical assistance of Mr. Elwood Mcduffie is gratefully acknowledged.

\section{REFERENCES}

1. Payne, M. R. and Rudnick, S. E. (1985) Cell Muscle Motil. 6, 141-184.

2. Maness, P. E. (1981) Cell Muscle Motil. 1, 335-373.

3. Byers, H. R., White, G. E. and Fujiwara, K. (1984) Cell Muscle Motil. 5,83-137.

4. Hendricks, M. and Weintraub, H. (1981) Proc. Natl. Acad. Sci. U.S.A. 78, 5633-5637.

5. Leonardi, C. L., Warren, R. H. and Rubin, R. W. (1982) Biochim. Biophys. Acta 720, 154-162.

6. Matsumura, F., Lin, J. J.-C., Yamashiro-Matsumura, S., Thomas, G. P. and Topp, W. C. (1983) J. Biol. Chem. 258, 13954-13964.

7. Leavitt, J., Latter, G., Lutomski, L., Goldstein, D. and Burbeck, S. (1986) Mol. Cell. Biol. 6, 2721-2726. 
8. Cooper, H. L., Bhattacharya, B., Bassin, R. H. and Salomon, D. S. (1987) Cancer Res. 47, 4493-4500.

9. Cooper, H. L., Feuerstein, N., Noda, M. and Bassin, R. H. (1985) Mol. Cell. Biol. 5, 972-983.

10. MacLeod, A. R. and Gooding, C. (1988) Mol. Cell. Biol. 8, 433-440.

11. MacLeod, A. R., Houlker, C., Reinach, F. C., Smillie, L. B., Talbot, K., Modi, G. and Walsh, F. S. (1985) Proc. Nat. Acad. Sci. USA 82, 7835-7839.

12. Wieczorek, D. F., Smith, C. W. J. and Nadal-Ginard, B. (1988) Mol. Cell. Biol. 8, 679-694.

13. Lees-Miller, J. P., Goodwin, L. O. and Helfman, D. M. (1990) Mol. Cell. Biol. 10, 1729-1742.

14. Helfman, D. M., Cheley, S., Kuismanen, E., Finn, L. A. and Kataoka-Yamawaki, Y. (1986) Mol. Cell. Biol. 6, 3582-3595.

15. Shi, Z. R., Tsao, D. and Kim, Y. S. (1983) Cancer Res. 43, 4045-4049.

16. Johnson, V. G., Schlom, J., Paterson, A. J., Bennett, J., Magnani, J. L. and Colcher, D. (1986) Cancer Res. 46, 850-857.

17. Sheer, D. G., Schlom, J. and Cooper, H. L. (1988) Cancer Res. 48, 6811-6818.

18. Guadagni, F., Witt, P. L., Robbins, P., Schlom, J. and Greiner, J. W. (1990) Cancer Res. 50, 6248-6255.

19. Bhattacharya, B., Prasad, G. L., Valverius, E. M., Salomon, D. S. and Cooper, H. L. (1990) Cancer Res. 50, 2105-2112.

20. Ebashi, S., Toyo-Oka, T. and Nonomura, Y. (1975) J. Biochem. (Tokyo) 78, 859-861.

21. Maniatis, T., Fritsch, E. F. and Sambrook, J. (1989) Molecular cloning, 2nd Edition. Cold Spring Harbor N.Y, Cold Spring Harbor Laboratory.

22. Meissner, P. S., Sisk, W. P. and Berman, M. L. (1987) Proc. Nat. Acad. Sci. U.S.A. $84,4171-4175$.

23. Sanger, F., Nicklen, S. and Coulson, A. R. (1977) Proc. Nat. Acad. Sci. USA. 74, 5463-5467.

24. Feinberg, A. P. and Vogelstein, B. (1983) Anal. Biochem. 132, 6-13. 